\title{
Roasting Conditions, Grinding Level and Brewing Method Highly Affect the Healthy Benefits of A Coffee Cup
}

Carla Severini*, Antonio Derossi, Ilde Ricci, Rossella Caporizzi and Anna Fiore

Department of Sciences of Agriculture, Food and Environment (SAFE), University of Foggia, Italy

Abstract

Background: The coffee drinking habits strongly vary as effect of several points, such as culture, lifestyle, social behavior, preferences, and economic aspects. However, it has been widely recognized that regularly drinking two or three coffees per day provides several health benefits. Nevertheless, the total intake in healthy compounds is largely affected by several variables among which the roasting, the grinding and the brewing method are the most important. On these pillars we have analyzed the effect of roasting, grinding and three brewing methods on the content in phenols, caffeine and antioxidants of coffee samples.

Methods: Three roasting degrees (light, medium and dark) and three grinding levels (fine, fine-coarse and coarse) were used to prepare Espresso, American and Turkish coffee samples for a total of 27 experimental conditions. Physical and chemical analyses as well as caffeine content, polyphenols and antioxidant activity were analyzed for each experimental condition.

Results: As effect of roasting, the antioxidant activity of coffee brew increased due to melanoidins produced at high temperature while the 'native' polyphenols of the green beans were significantly lost during roasting. Grinding level affected the kinetic extraction more than pressure, dose and particle size although a significant variation was always observed. As consequence regular espresso of $25 \mathrm{~mL}$ may contain from 80 to $120 \mathrm{mg}$ of caffeine depending of the variance in grinding process. Overall, a regular cup $(200 \mathrm{~mL})$ of American coffee resulted to contain average values of 280-350 mg of caffeine, 500-1200 $\mathrm{mg}$ of gallic acid and 500-1200 mg trolox.

Conclusion: American coffee was the richest in caffeine, polyphenols and antioxidant activity when considering a regular coffee commonly consumed at bar. A more precise standardization of the grinding, when consuming coffee at bar, is one of the most important future step to tackle the wide variability in quality estimated among repeated coffees.

\section{Introduction}

All around the world the $80-90 \%$ of adults regularly consume coffee but their drinking habits dramatically changes on the basis of lifestyle, social behavior, preferences, economic aspects as well as the age. For instance, young people widely prefer more energy drinks than coffee. However, coffee consumption is continuously growing due to the recent attention of consumers concerning the healthy benefits of coffee beverage. By now a wide literature appears to be concluding that coffee consumption is related to a reduced risk of type 2 diabetes, coronary heart disease, Alzheimer's disease, Parkinson's disease and several cancers [1]. These effects seem caused by the strong antioxidant activity, the inhibition of lipid peroxidation [2-4], as well as the significant increase of plasma glutathione concentration, because of the presence in coffee of diterpenes (cafestol), polyphenols and melanoidins depending on the type and origin of coffee beans, roasting degree and brewing procedure [5]. Thus, several authors speak of "coffee paradox", finding in coffee, after roasting, a number of potentially dangerous compounds, if considered alone, but very healthy, when considered together in the beverage.

However, from a technological point of view, the making of a good coffee is not too easy. A number of technological steps have to be carried out to obtain the final product (coffee beverage) starting from the raw material (green coffee) (Figure 1) and some of them have a crucial importance in affecting the quality of coffee brew.

At first, as reported elsewhere coffee species, origins and blending represent the starting points for the chemical differences among coffee brews. Generally belong to genus Coffea about 70 species but the Coffea Arabica (Arabica) and Coffea canephora (Robusta) are commercially the most important. They display important chemical, physical and sensorial differences caused by the different climatic conditions in which they are developed [6]. As example, the Robusta contains more caffeine than the Arabica with values in the range of $1.2-2.4 \%$ and $0.9-1.5 \%$, respectively. However, apart these differences, it is worth noting that the blending of Arabica and Robusta in different ratios is a common practice in coffee industries by which they obtain unique sensorial properties enabling to increase the international competitiveness.

During roasting a huge number of changes occur on the coffee beans. Their volume becomes twice the green beans, while the weight decreases of $15-20 \%$ mainly for water evaporation. Also, chemical composition significantly modifies. Caffeine content decreases due to sublimation and dragging with vapor, while several thousands of chemical compounds are obtained improving the sensorial profile of the beans and enriching their antioxidant activity.

"Corresponding Author: Dr. Carla Severini, Department of Sciences of Agriculture, Food and Environment (SAFE), University of Foggia, Italy, Tel: +39 0881589222; E-mail: carla.severini@unifg.it.

Citation: Severini C, Derossi A, Ricci I, Caporizzi R, Fiore A, et al. (2017) Roasting Conditions, Grinding Level and Brewing Method Highly Affect the Healthy Benefits of A Coffee Cup. Int J Clin Nutr Diet 4: 127. doi: https://doi. org/10.15344/2456-8171/2018/127

Copyright: (c) 2018 Severini et al. This is an open-access article distributed under the terms of the Creative Commons Attribution License, which permits unrestricted use, distribution, and reproduction in any medium, provided the original author and source are credited. 
The grinding is the closest step to the making coffee cup that hardly changes its quality. Being all the brewing methods based on solid-liquid extraction, the particle size of ground coffee has a great influence on sensorial and healthy properties of coffee. Among those commonly used around the world several differences exist. As example, for the preparation of Turkish coffee the finest particles are used producing 15,000-35,000 particles from each roasted bean, while 3,500 and 100-300 particles are usually obtained for Espresso and French coffees, respectively [7]. Although the general idea of a greater extraction when using smaller particles is correct, at the same time it is too general resulting in a loss of significant information on the water percolation pathway. For example, to make an espresso coffee, when very fine ground coffee is used, the coffee cake could be close to its percolation threshold, notably reducing the extraction of chemical compounds. On the other hand, by using coarse particles the extraction rate could increase too much reducing the time of contact between hot water and coffee particles. As a result a dilution effect could be the most important. Grinding uniformity is of crucial interest for obtaining a homogenous quality of coffee cup and it is still a challenge when drinking coffee at bar or at home. For instance, when grinding operation is performed at bar variables such as blade grinder, conical, or flat burrs grinder are very effective for the dimensional variability of coffee particles.

Speaking on the different coffee brewing, the 'best way to make a coffee cup' does not exist. Only consumers decide what is better or worse as a function of their preferences. However, despite sensorial properties, brewing methods also affect the healthy properties of coffee as a consequence of very different extraction conditions. Espresso coffee is obtained by using hot water under pressure which passes through a compacted coffee cake. For a regular coffee of 25

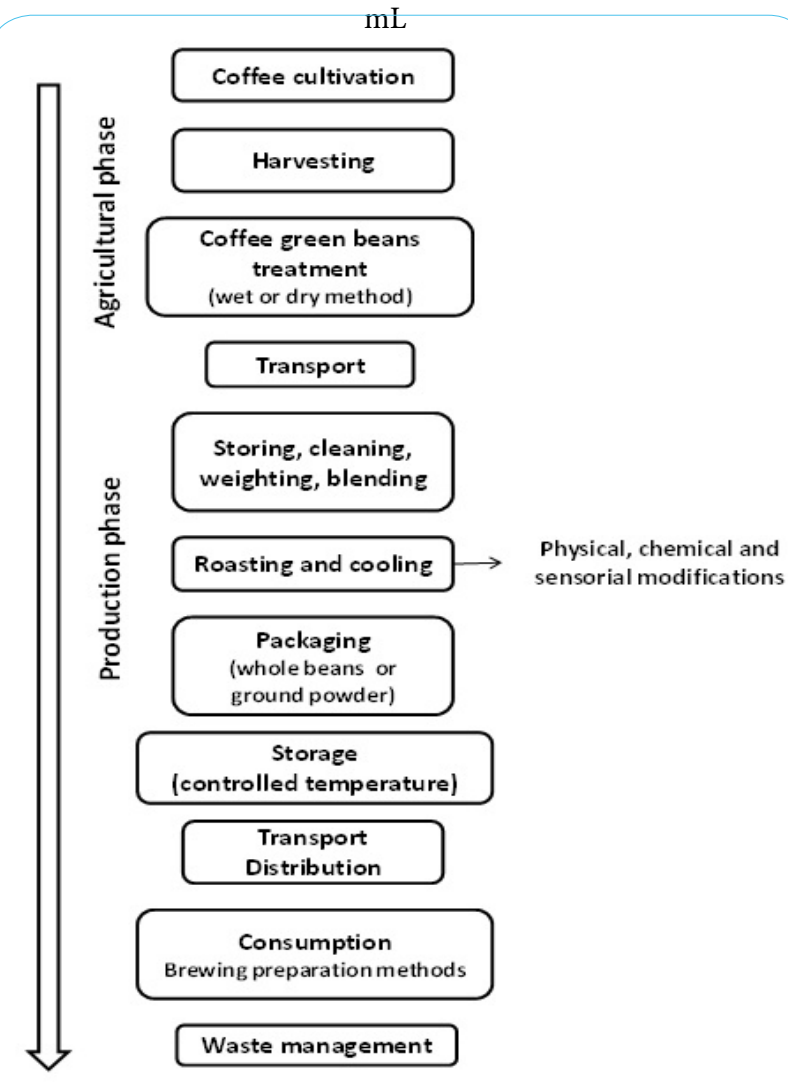

Figure 1: Schematic representation of coffee supply chain around $25 \mathrm{~s}$ are needed, but in many places ristretto or lungo coffees are preferred with a volume of about 15 and $30 \mathrm{~mL}$ respectively. Of course, depending on the total volume and its extraction time, the healthy compounds dissolved in coffee cup may exhibit a great variability. Also, due to the extraction under pressure the above reported effect of the particle size is emphasized. The caffeine contents of espresso coffee brews were found from 2.1 to $4.2 \mathrm{mg} / \mathrm{mL}$ and lower than $3.2 \mathrm{mg} / \mathrm{mL}$ when using a ground coffee fine and coarse, respectively [8-11]. However, many other variables may affect the properties of an Espresso coffee, such as the dose of coffee ground that affects the aroma and bioactive compounds of the brew [12]. Andueza et al. [13] found a caffeine content of $1.80,1.88$ and $2.21 \mathrm{mg} / \mathrm{mL}$ when using 6.5, 7.5 and $8.5 \mathrm{~g}$ of coffee ground. In addition, as reported from Severini et al. [8], the pressure on the top of coffee cake (i.e. tamping) may affect the chemical composition of espresso coffee. Finally, not less important are other variables such as water temperature, water pressure, extraction time as well as the use of filter holder at 1 or 2 cup as highlighted from other authors $[8,10]$. A wide scientific literature analyzing the effects of several variables such as roasting degree, grinding level, powder/water ratio, etc., is available [14-16].

The American or filtered coffee is obtained by the percolation of hot water at $92-96^{\circ} \mathrm{C}$ through coffee ground contained in a paper filter. Usually the extraction time to obtain American coffee is significantly higher than the Espresso coffee and this produces two main important effects: 1 . A prolonged extraction of chemical compounds; 2 . The dilution effect of water during the last phases of percolation. Usually, the content in caffeine is $\sim 0.6-0.7 \mathrm{mg} / \mathrm{mL}$ that is lower than Espresso coffee. Nevertheless, when considering a total volume of an American coffee $(354 \mathrm{~mL})$, the total intake of caffeine for the consumers would be of $154 \mathrm{mg}$ [17] due to the aforementioned longer extraction time.

However, also for this brewing method the variability of the quality of coffee brew may be wide. For instance, some authors found contents in caffeine of 0.57 and $1.15 \mathrm{mg} / \mathrm{mL}$ when using Arabica and Robusta, respectively. In addition, drinking out coffee it has been observed that the content in caffeine of filtered coffee may vary from $51 \mathrm{mg} / \mathrm{cup}$ in Starbucks to $322 \mathrm{mg} / \mathrm{cup}$ in Patisserie Francoise. This is because the extraction conditions, as above reported, may be set in very different manners. In addition to these two brewing methods other preparations may be used. Some of these are restricted in small geographic area due to their historical relationship such as Neapolitan pot in southern Italy, while others are more popular such as the use of Moka, French press or plunger coffee and Turkish coffee. The last of these is the most ancient brewing method based on two repeated heating until boiling water. However, very few experiments on the healthy properties and on the affecting variables of Turkish coffee have been performed in details.

All the above considerations motivated the main aim of our paper that is the study of the effects of roasting level, grinding degree and three preparation methods (Espresso, American and Turkish) on the content in cup of polyphenols, caffeine and the antioxidant activity.

\section{Materials and Methods}

$300 \mathrm{~g}$ of a commercial blend of green beans were roasted at $150^{\circ} \mathrm{C}$ and $400 \Omega$ for 6, 9 and 12 min, to obtain 'Light', 'Medium' and 'Dark' roasted coffee beans, respectively. The lipid fraction of coffee powder was extracted in hexane at $25^{\circ} \mathrm{C}$ for $4 \mathrm{~h}$ with a $1: 6(\mathrm{w} / \mathrm{v})$ ratio. Peroxide value (PV) was determined following the AOCS method [18]. The $\mathrm{pH}$ of the brew was detected by a $\mathrm{pH}$-meter previously calibrated. Also, 
acidity was measured by titration of $20 \mathrm{~mL}$ of coffee brew at room temperature with $\mathrm{NaOH} 0.1 \mathrm{~N}$ until pH 7.00 [19]. Total solids content were gravimetrically measured by drying about $3 \mathrm{~mL}$ (beverages) of coffee at $105^{\circ} \mathrm{C}$ until constant weight [20]. The particle size distribution of the ground coffee was carried out by using a laser granulometer Analysette 22 with the Dry dispersion unit and the results were expressed as bimodal particle size distribution and distribution density [21]. Three brewing methods such as Espresso, American and Turkish, were chosen on the basis of their wide consumptions all over the world [2]. The effects of three grinding levels: 6, 6.5 and 7 , corresponding to fine, fine-coarse and coarse coffee grounds, were analyzed. The choice of these grinding levels was performed on the basis of previous studies $[8,10,22]$. Caffeine content was measured by using the method described by Skoog et al. [23], total phenols were determined according to the method of Singleton and Rossi [24] and Antioxidant assay was performed following the procedure described by Brand-Williams et al. [25], all methodologies were performed with minor modifications as we have reported in a previous paper [26].

\section{Results and Discussion}

In some recent papers we have investigated the influence of roasting level and grinding level on some characteristics of espresso coffee [8$10,22]$. As expected, $\mathrm{pH}$ did not vary because of the strong buffer power of coffee beverage, but the decrease of the titratable acidity can be appreciated depending on the grinding level of powder (Table 1). The typical bell behavior, from light to dark roasted coffee, has remembered us what is well known, that is the medium roasted coffee (specifically American) is more acid than the dark one like Italian.

The content in total solids have been affected more by grinding level than by roasting level, likely because of the differences in microstructure of coffee cake changed the pathway of hot water during percolation modifying the amount of extracted components. On the contrary the content of caffeine was mainly affected by the roasting level exhibiting the highest value for dark rather than the light roasted, confirming the results of other Authors [27]. However, nowadays we know that it is an advantage for the human health.
Concerning other important healthy compounds, it is worth noting as polyphenols have decreased while the antioxidant activity has increased. Reasonably, the antioxidant activity has especially derived from compounds obtained during roasting, such as melanoidins. In fact, the stronger is the roasting process while the greater is the antioxidant activity. This effect resulted evident also from the peroxide value measured on lipids extracted from the coffee powder (Table 2), which was higher for medium roasted coffee, with a higher content of polyphenols than melanoidins.

Table 3 reports the particle size distribution for 3 different levels of grinding. The main role played by grinding level has been already investigated by the Authors [28] and has been also confirmed by a comparison among several variables affecting some characteristics of coffee beverage. By fitting the changes in volume of coffee brew as a function of extraction time, the highest increase of determination coefficient was obtained for the grinding $\left(\mathrm{R}_{\mathrm{adj}}=0.96\right)$ that means that this is the most affecting variable for the kinetic of extraction (Table 4).

However, taking into account the grinding level of 6 , which produce the finest coffee ground, an Espresso beverage of $25 \mathrm{~mL}$ could be obtained in a time ranged from 21 to $24 \mathrm{~s}$, with a content of caffeine "in cup" ranging from 80 to $120 \mathrm{mg}$ (Figure 2). This is the effect of the inside variability in grinding, that is a great technological problem for the industrial production of coffee.

This result is all the more important if we consider that the variability of particle size distribution of ground coffee, significantly affects the percolation rate, the caffeine content, the solid content, the $\mathrm{pH}$ and acidity, as a consequence of changes in the microstructural properties of the coffee cake, such as porosity and the percolation pathway. Thus, in sight of this, the performances of grinder devices should be strongly improved.

As concerns another aspect, which greatly affects the quality "in cup" of coffee, there are several different methods worldwide used to prepare the coffee beverage. The Italian espresso, the plunger French, the filtered American, the boiled Turkish, the percolated Italian "moka",

\begin{tabular}{|c|c|c|c|c|c|c|c|c|c|c|c|c|c|c|c|c|c|c|c|}
\hline \multirow{2}{*}{$\begin{array}{l}\begin{array}{l}\text { Roasting } \\
\text { level }\end{array} \\
\text { Light }\end{array}$} & \multirow{2}{*}{\begin{tabular}{|l}
$\begin{array}{l}\text { Grinding } \\
\text { level }\end{array}$ \\
Fine
\end{tabular}} & \multicolumn{3}{|l|}{$\mathrm{pH}$} & \multicolumn{3}{|c|}{$\begin{array}{l}\text { Total Solids } \\
\text { Content (TSC) } \\
\text { (g d.w./mL) }\end{array}$} & \multicolumn{3}{|c|}{$\begin{array}{l}\text { Titratable acidity } \\
(\mathrm{TA}) \\
(\mathrm{mL} \mathrm{NaOH} / \mathrm{mL} \\
\text { brew) }\end{array}$} & \multicolumn{3}{|c|}{$\begin{array}{l}\text { Antioxidant } \\
\text { activity (AA) } \\
(\mathrm{mg} \text { Trolox } / \mathrm{mL})\end{array}$} & \multicolumn{3}{|c|}{$\begin{array}{l}\text { Total phenol } \\
\text { content (TPC) } \\
\text { (mg Gallic acid / } \\
\mathrm{mL})\end{array}$} & \multicolumn{3}{|c|}{$\begin{array}{l}\text { Caffeine (C) } \\
(\mathrm{mg} / \mathrm{mL})\end{array}$} \\
\hline & & 5.5 & \pm & 0.05 & 61.2 & \pm & 3.1 & 2.56 & \pm & 0.25 & 6.96 & \pm & 0.4 & 24.21 & \pm & 2.03 & 2.71 & \pm & 0.04 \\
\hline & $\begin{array}{l}\text { Fine- } \\
\text { Coarse }\end{array}$ & 5.6 & \pm & 0.04 & 51.2 & \pm & 3.3 & 1.91 & \pm & 0.17 & 10.7 & \pm & 0.3 & 20.00 & \pm & 1.26 & 2.61 & \pm & 0.03 \\
\hline & Coarse & 5.6 & \pm & 0.06 & 52.3 & \pm & 3.8 & 1.79 & \pm & 0.07 & 11.5 & \pm & 0.2 & 17.3 & \pm & 1.16 & 2.64 & \pm & 0.02 \\
\hline \multirow[t]{3}{*}{ Medium } & Fine & 5.1 & \pm & 0.06 & 63.5 & \pm & 1.6 & 4.88 & \pm & 0.89 & 9.76 & \pm & 0.3 & 20.7 & \pm & 0.73 & 2.81 & \pm & 0.03 \\
\hline & $\begin{array}{l}\text { Fine- } \\
\text { Coarse }\end{array}$ & 5.1 & \pm & 0.02 & 55.6 & \pm & 3.7 & 4.73 & \pm & 0.29 & 10.7 & \pm & 0.3 & 19.5 & \pm & 1.35 & 2.78 & \pm & 0.04 \\
\hline & Coarse & 5.1 & \pm & 0.06 & 52.1 & \pm & 1.6 & 3.96 & \pm & 0.41 & 12.1 & \pm & 0.2 & 17.3 & \pm & 2.48 & 2.73 & \pm & 0.1 \\
\hline \multirow[t]{3}{*}{ Dark } & Fine & 5.7 & \pm & 0.07 & 51 & \pm & 1.8 & 2.49 & \pm & 0.18 & 13.5 & \pm & 0.2 & 14 & \pm & 0.59 & 2.86 & \pm & 0.01 \\
\hline & $\begin{array}{l}\text { Fine- } \\
\text { Coarse }\end{array}$ & 5.7 & \pm & 0.07 & 61.8 & \pm & 2.7 & 2.82 & \pm & 0.67 & 12.7 & \pm & 0.2 & 15.6 & \pm & 0.59 & 2.99 & \pm & 0.02 \\
\hline & Coarse & 5.7 & \pm & 0.08 & 51 & \pm & 4 & 2.41 & \pm & 0.16 & 12.9 & \pm & 0.1 & 14.5 & \pm & 0.58 & 2.97 & \pm & 0.16 \\
\hline
\end{tabular}

Table 1: Main chemical composition of coffee brews as a function of roasting and grinding levels.

Statistics: by the ANOVA 1-way, TSC have been not significantly different; $\mathrm{pH}$ and TA have been significantly different only for medium roasted coffee; AA and TPC have been significantly different for all the samples; $\mathrm{C}$ has been significantly different for dark regardless of the granulometry. 
Citation: Severini C, Derossi A, Ricci I, Caporizzi R, Fiore A, et al. (2017) Roasting Conditions, Grinding Level and Brewing Method Highly Affect the Healthy Benefits of A Coffee Cup. Int J Clin Nutr Diet 4: 127. doi: https://doi.org/10.15344/2456-8171/2018/127

Page 4 of 6

the simply solubilized (instant) are some of the traditional methods for coffee preparation. However, new methods are continuously set and patented, such as the single-serve pod and capsule for espresso coffee as domestic method, the more recent single-serve capsule for American filtered coffee [29] and a new canned brew, obtained from a cold infusion.

\begin{tabular}{|l|l|l|l|l|}
\hline Roasting degree & $\begin{array}{c}\text { Time of roasting } \\
(\mathrm{min})\end{array}$ & \multicolumn{3}{|c|}{$\begin{array}{c}\text { Peroxides value } \\
\text { (mEq O2 active/kg of oil) }\end{array}$} \\
\hline Green & - & - & & \\
\hline Light & 6 & 3.98 & \pm & 0.82 \\
\hline Medium & 9 & 5.83 & \pm & 0.07 \\
\hline Dark & 12 & 5.45 & \pm & 0.10 \\
\hline
\end{tabular}

Table 2: Assessment of peroxides value of coffee powder for different roasting degree

\begin{tabular}{|l|l|l|l|}
\hline $\mathrm{Q} 3(\mathrm{x}) \%$ & Fine & Fine-coarse & Coarse \\
\hline $10 \%$ & $\mathrm{x}<20.9$ & $\mathrm{x}<28.16$ & $\mathrm{x}<51.11$ \\
\hline $50 \%$ & $20.9<\mathrm{x}<226.93$ & $28.16<\mathrm{x}<337.69$ & $\begin{array}{l}51.11<\mathrm{x}< \\
502.51\end{array}$ \\
\hline $30 \%$ & $226.93<\mathrm{x}<372.97$ & $\begin{array}{l}337.69<\mathrm{x}< \\
502.51\end{array}$ & $\begin{array}{l}502.51<\mathrm{x}< \\
677.05\end{array}$ \\
\hline $10 \%$ & $\mathrm{x}>372.97$ & $\mathrm{x}>502.51$ & $\mathrm{x}>677.05$ \\
\hline
\end{tabular}

Table 3: Particles size distribution of coffee ground for different grinding levels

\begin{tabular}{|l|l|}
\hline Variables & Explained part (Radj.) \\
\hline Averaged & 0.55 \\
\hline Pressure & 0.64 \\
\hline Weight & 0.63 \\
\hline Grinding level & 0.96 \\
\hline Pressure, weight & 0.54 \\
\hline Grinding level, weight & 0.96 \\
\hline Grinding level, pressure & 0.97 \\
\hline
\end{tabular}

Table 4: Explained part $\left(\mathrm{R}_{\text {adj. }}\right)$ of fit describing the effect of variables on the changes in volume of coffee brew

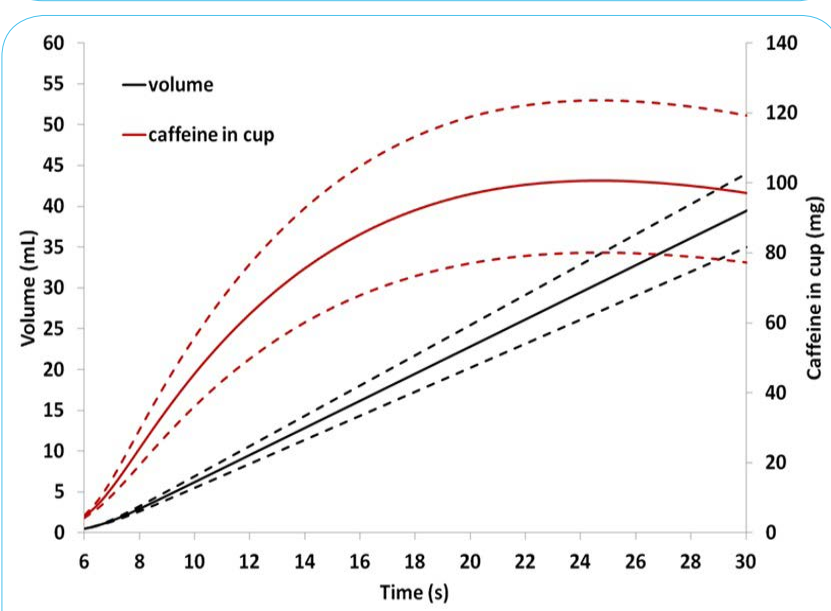

Figure 2: Estimated volume and caffeine content of espresso coffee as a function of extraction time. Data obtained by taking into account a grinding level of 6 . Dashed lines represent $95 \%$ of confidence interval.
Each technique applies different water/coffee ratios, granulometry of coffee powder, water temperature, extraction time and rate, water pressure, final volume of beverage.

The research results stated that different preparation methods involve different content of polyphenols, caffeine, total solids as well as different antioxidant activity and volatile profiles. For instance, López-Galilea et al. [30] have studied the content of caffeine for 4 different extraction methods, American, French, Italian moka and espresso, starting from a commercial blend of Arabica and Robusta, and have found that the caffeine content could vary, "in cup", from 25 to $140 \mathrm{mg}$ (Table 5).

\begin{tabular}{|l|l|l|l|}
\hline Brewing method & $\begin{array}{l}\text { Caffeine } \\
(\mathrm{mg} / \mathrm{mL})\end{array}$ & $\begin{array}{l}\text { Volume of } \\
\text { coffee cup }(\mathrm{mL})\end{array}$ & $\begin{array}{l}\text { Total caffeine } \\
\text { content in cup }\end{array}$ \\
\hline Filter (American) & 0.22 & 400 & 88 \\
\hline Plunger (French) & 0.20 & 500 & 100 \\
\hline Mocha (Italian) & 0.28 & 500 & 140 \\
\hline Espresso (Italian) & 0.63 & 40 & 25 \\
\hline
\end{tabular}

Table 5 - Caffeine content of coffee brew obtained by using different brewing method (30).

In figure 3 the comparison of caffeine content, overall polyphenols content and antioxidant activity of regular cups of the Italian espresso, the American and the Turkish coffee are shown considering also the effect of 3 different grinding levels.

Results confirm that the American coffee contains the greatest amount of caffeine, followed by Turkish one and Espresso. The same order may be observed for phenolic content and antioxidant activity.

However, if the caffeine content is considered per $\mathrm{mL}$ of beverage, the greatest concentration has been found in espresso coffee, followed by the Turkish one and American (26). Thus, the volume have decided how much caffeine or other healthy components we intake with a cup of coffee.

\section{Conclusions}

The quality of a coffee cup depends on a large number of variables which may be properly adjusted only if technicians have deep technological skills.

Although the sample of Espresso coffee has exhibited the highest concentration in caffeine, polyphenols and antioxidant activity, a cup American coffee enables to assume the maximum amount of these compounds. This is because among the most important variables, the total volume is the factor controlling the overall content in chemical compounds.

Also, an additional step too often underestimated is the grinding, which affects not only the particle size distribution but also its homogeneity. From an industrial point of view, as well as at coffee shops, the lack of devices able to guarantee the precise characteristics of powder, could become a serious problem for the quality of coffee brew, even though some other technological aspects, such as the compactness of the coffee cake and its porosity, should be deepened to achieve the optimization of the extraction process of coffee. 
Citation: Severini C, Derossi A, Ricci I, Caporizzi R, Fiore A, et al. (2017) Roasting Conditions, Grinding Level and Brewing Method Highly Affect the Healthy Benefits of A Coffee Cup. Int J Clin Nutr Diet 4: 127. doi: https://doi.org/10.15344/2456-8171/2018/127

Page 5 of 6

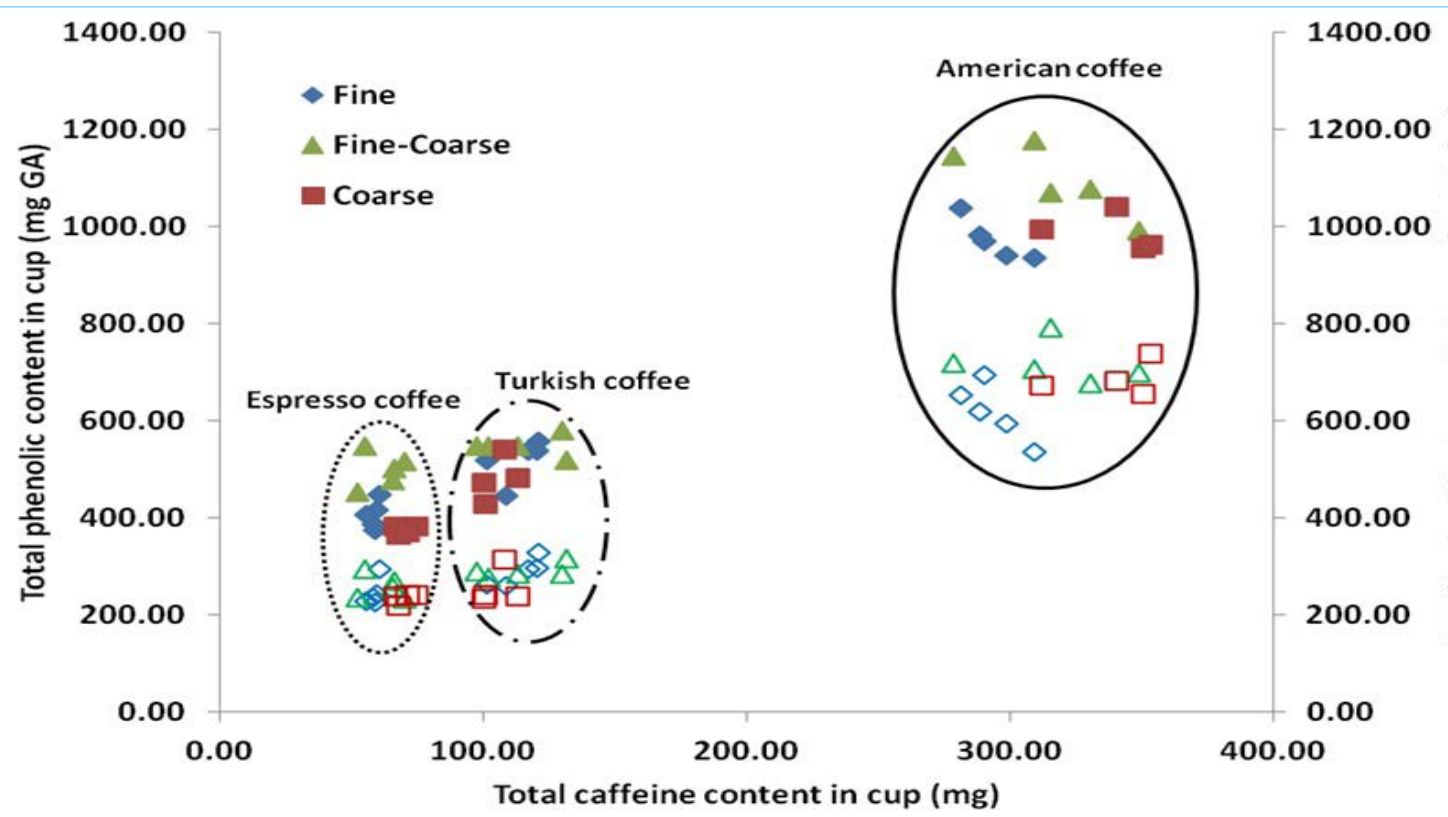

Figure 3 - Changes in caffeine content, total phenols and antioxidant activity of regular cups of Espresso, Turkish and American coffees. Closed points indicates total phenolic content; Open points indicates total antioxidants capacity.

\section{Competing Interests}

The authors declear that no competing interests exist.

\section{Author's contributions}

Carla Severini makes substantial contributions to the conception and design and in drafting the manuscript; Antonio Derossi makes substantial contributions to the design, acquisition and interpretation of data; Ilde Ricci, Rossella Caporizzi and Anna Fiore have been involved in acquisition data and critically revising the manuscript.

\section{Aknowledgements}

The authors gratefully acknowledge ESSSE Caffè S.p.A. for providing coffee samples and supporting the research.

\section{References}

1. Coughlin JR, Nehlig A (2012) Coffee and cancer: A benefit-risk evaluation of the experimental and epidemiological evidence, Proceedings of the 24th International Conference on Coffee Sciences.

2. Severini C, Derossi A, Ricci I, Fiore AG, Caporizzi R, et al. (2017) How Much Caffeine in Coffee Cup? Effects of Processing Operations, Extraction Methods and Variables. In: Latosinska JN (1st Ed) The Question of Caffeine, InTech, Croatia 45-85.

3. Napolitano A, Fogliano V, Tafuri A, Ritieni A (2007) Natural occurrence of ochratoxin $A$ and antioxidant activities of green and roasted coffees and corresponding byproducts. J Agric Food Chem 55: 10499-10504.

4. Salomone F, Li Volti G, Vitaglione P, Morisco F, Fogliano V, et al. (2014) Coffee enhances the expression of chaperones and antioxidant proteins in rats with nonalcoholic fatty liver disease. Transl Res 163(6): 593-602.

5. Esposito F, Morisco F, Verde V, Ritieni A, Alezio A, et al. (2003) Moderate coffee consumption increases plasma glutathione but not homocysteine in healthy subjects. Aliment PharmacolTher 17(4): 595-601.

6. Mazzafera P, Crozier A, Magalhaes C (1991) Caffeine metabolism in Coffea arabica and other species of coffee. Phytochemistry 30: 3913-3916.

7. Ephraim D. 2016.
8. Severini C, Derossi A, Fiore AG, De Pilli T, Alessandrino O, et al. (2016) How the variance of some extraction variables may affect the quality of espresso coffees served at coffee shop? J Sci Food Agric 96(9): 30233031.

9. Andueza S, de Peña MP, Cid C (2003) Chemical and sensorial characteristics of espresso coffee as affected by grinding and torrefacto roast. J Agric Food Chem. 51: 7034-7039.

10. Severini C, Ricci I, Marone M, Derossi A, De Pilli T, et al. (2015) Changes in aromatic profile of espresso coffee as a function of grinding grade and extraction time: A study by electronic nose system. J Agric Food Chem 63: 2321-2327

11. Gloess AN, Schonbachler B, Klopprogge B, D'Ambrosio L, Chatelain K et al. (2013) Comparison of nine common coffee extraction methods: Instrumental and sensory analysis. Eur Food Res Technol 236: 607-627.

12. Romani S, Severini C, Fiore AG, Pinnavaia GG (2004) Quality of espresso coffee: A study performed through Italian coffee shops, Proceedings of the 20th International Conference on Coffee Sciences.

13. Andueza S, Vila AM, de Peña MP, Cid C (2007) Influence of coffee/water ratio on the final quality of espresso coffee. J Sci Food Agric 87: 586-592.

14. Tfouni SAV, Carreiro LB, Teles CRA, Furlani RPZ, Cipolli KMVAB, et al. (2014) Caffeine and chlorogenic acids intake from coffee brew: Influence of roasting degree and brewing procedure. Int J Food SciTechnol 49: 747752.

15. Ludwig IA, Sanchez L, Cammerer B, Kroh LW, de Peña MP, et al. (2012) Extraction of coffee antioxidants: Impact of brewing time and method. Food Res 48: 57-64.

16. Bell LN, Wetzel CR, Grand AN (1996) Caffeine content in coffee as influenced by grinding and brewing conditions. Food Res Int 29: 785-789.

17. Caffeine Informer.

18. A.O.C.S. (1993) American oil Chemists' Society, 8-87

19. Gloess AN, Vietri A, Wieland F, Smrke S, Schönbächler B, et al. (2014) Evidence of different flavour formation dynamics by roasting coffee from different origins: On-line analysis with PTR-ToF-MS. Int J Mass Spectrom 365-366: 324-337.

20. A.O.A.C. (2000) Official Methods on Analysis, $17^{\circ}$ ed. Association of Official analytical Chemists, Washington, D.C.

21. Corrochano BR, Melrose JR, Bentley AC, Fryer PJ, Bakalis S (2015) A new methodology to estimate the steady-state permeability of roast and ground coffee in packed beds. J Food Eng 150: 106-116. 
Citation: Severini C, Derossi A, Ricci I, Caporizzi R, Fiore A, et al. (2017) Roasting Conditions, Grinding Level and Brewing Method Highly Affect the Healthy Benefits of A Coffee Cup. Int J Clin Nutr Diet 4: 127. doi: https://doi.org/10.15344/2456-8171/2018/127

22. Severini C, Derossi A, Fiore AG, Ricci I, Marone M (2016) The electronic nose system: study on the global aromatic profile of espresso coffee prepared with two types of coffee filter holders. Eur Food Res Technol 242: 2083-2091.

23. Skoog DA, Holler FJ, Crouch SR (2007) Determination of caffeine in beverages by high performance liquid chromatography. In: Skoog DA (6th Ed) Principles of Instrumental Analysis, Thomson, Brooks/Cole, Belmont, CA 1-13.

24. Singleton SL and Rossi JA (1965) Colorimetry of total phenolics with phosphomolybdic-phosphotungstic acid reagents. Am J EnolVitic 16: 144158.

25. Brand-Williams W, Cuvelier ME, Berset C (1995) Use of a free radical method to evaluate antioxidant activity. LWT- Food SciTechnol 28: 25-30.

26. Derossi A, Ricci I, Caporizzi R, Fiore A, Severini C (2017) How grinding levels and brewing methods (Espresso, American, Turkish) could affect the antioxidant activity and bioactive compounds in a coffee cup. J Sci Food Agric

27. Vignoli JA, Bassoli DG, Benassi MT (2011) Antioxidant activity, polyphenols, caffeine and melanoidins in soluble coffee: The influence of processing conditions and raw material. Food Chem 124: 863-868.

28. Severini C, Romani S, Cevoli C, Derossi A (2012) Quality 'in cup' of espresso coffee: data from over ten years of investigation, Proceeding of the 24th International Conference on Coffee Science.

29. Xiuju W, Joshua W, Yucheng F, Loong-Tak L (2016) Effects of capsule parameters on coffee extraction in single-serve brewer. Food Res Int 89: 797-805.

30. López-Galilea I, de Peña MP, Cid C (2007) Correlation of selected constituents with the total antioxidant capacity of coffee beverages: Influence of the brewing procedure. J Agric Food Chem 55: 6110-6117. 